\title{
Time trends in symptoms of mental illness in children and adolescents in Canada
}

\author{
Seanna E. McMartin MSc, Mila Kingsbury PhD, Jennifer Dykxhoorn BSc, Ian Colman PhD
}

Competing interests: None declared.

This article has been peer reviewed.

Correspondence to:

Ian Colman,

icolman@uottawa.ca

CMAJ 2014. DOI:10.1503

/cmaj.140064

\begin{abstract}
Background: Existing research and media reports convey conflicting impressions of trends in the prevalence of mental illness. We sought to investigate trends in the prevalence of symptoms of mental illness in a large population-based cohort of Canadian children and adolescents.
\end{abstract}

Methods: We obtained population-based data from the National Longitudinal Survey of Children and Youth. Every 2 years, participants completed self-reported measures of mental illness indicators, including conduct disorder, hyperactivity, indirect aggression, suicidal behaviour, and depression and anxiety. We analyzed trends in mean scores over time using linear regression.

Results: We evaluated 11725 participants aged 10-11 years from cycles 1 (1994/95) through 6 (2004/05), 10574 aged 12-13 years from cycles 2 (1996/97) through 7 (2006/07), and 9835 aged 14-15 years from cycles $3(1998 / 99)$ through 8
(2008/09). The distribution of scores on depression and anxiety, conduct and indirect aggression scales remained stable or showed small decreases over time for participants of all ages. The mean hyperactivity score increased over time in participants aged 10-11 years (change per 2-year cycle: $0.16,95 \% \mathrm{Cl} 0.02$ to 0.12 ) and those aged $12-13$ years $(0.13,95 \% \mathrm{Cl} 0.09$ to $0.18)$. Over time, fewer participants aged $12-13$ years $(0.40 \%$ per cycle, $95 \% \mathrm{Cl}-0.78$ to -0.07$)$ and aged $14-15$ years $(0.56 \%$ per cycle, $95 \% \mathrm{Cl}$ -0.91 to -0.23 ) reported attempting suicide in the previous 12 months.

Interpretation: With the exception of hyperactivity, the prevalence of symptoms of mental illness in Canadian children and adolescents has remained relatively stable from 1994/95 to 2008/09. Conflicting reports of escalating rates of mental illness in Canada may be explained by differing methodologies between studies, an increase in treatment-seeking behaviour, or changes in diagnostic criteria or practices.
$\mathrm{P}$ opular media tends to perpetuate the idea that the prevalence of mental disorders is increasing. However, research supporting this position has been inconsistent. Several studies have shown increases in recent years, ${ }^{1,2}$ including among adolescents. ${ }^{3-7}$ These studies have included parent reports from population samples $^{3,4}$ and physician diagnoses from electronic medical records. ${ }^{6}$ In contrast, other studies have reported that the rates of mental illness have decreased or remained stable over time..$^{8-11}$ To appropriately plan services and policies, a proper understanding of trends in adolescent mental health is crucial. This is particularly relevant in Canada, where policy regarding mental health is currently being reconsidered under such frameworks as the Mental Health Commission of Canada's 2012 mental health strategy, "Changing Directions, Changing Lives."12

Many methodologic challenges make it difficult to draw conclusions regarding trends in mental illness. The conflicting reports of chang- ing rates of mental illness in the population may be partially explained by changes in diagnostic criteria, differences in assessment methods or variations in official reporting practices. ${ }^{4}$ For example, one study found that while diagnosed depression decreased, the incidence of depressive symptoms noted by health professionals increased by threefold from 1996 to $2006 .{ }^{13}$ These changes may not represent a real change in the rates of depression or depressive symptoms, but rather a change in clinical practice.

Canada's National Longitudinal Survey of Children and Youth repeatedly included a series of questions from 1994/95 to 2008/09 relevant to many aspects of mental health in children and adolescents, including assessments of conduct disorder, hyperactivity, aggression, depression and anxiety, and suicidal thinking and behaviour. Our primary objective was to investigate trends in the prevalence of symptoms in these areas in 3 specific age groups: $10-11,12-13$ and $14-15$ years. 


\section{Methods}

\section{Study design}

This study used data from the National Longitudinal Survey of Children and Youth, which involves a population-based cohort of Canadian children and adolescents followed prospectively every 2 years by Statistics Canada since 1994/95. ${ }^{14}$ The cohort is considered nationally representative, with the exception of children living on First Nations reserves or Crown lands, in institutions and in some remote regions. This study was designed to collect information about multiple aspects of child health and development. The follow-up rate for the National Longitudinal Survey of Children and Youth from cycle 1 (1994/95) to cycle $8(2008 / 2009)$ was $61 \% .{ }^{15}$ Further details about the cohort, including study design and response rates (mostly above $80 \%$ at each wave), are described elsewhere. ${ }^{14,15}$

The survey included numerous assessments related to child and adolescent mental health. The behaviour scale was adapted from questionnaires used in the Montreal Longitudinal Survey and the Ontario Child Health Study, which were designed to identify children who would most likely qualify for a psychiatric diagnosis based on symptom criteria for the revised 3rd edition of the Diagnostic and Statistical Manual of Mental Disorders. ${ }^{16}$ This scale has been used in previous studies of child and adolescent adjustment, and has shown good psychometric properties. ${ }^{17,18}$

In each cycle, participants aged 10 years or older were asked to self-report the frequency of various feelings and behaviours in the past week, with 3 possible responses ranging from "never or not true" to "often or very true." Each item was assigned a score of 0 to 2 (higher scores indicating a greater degree of mental health problems). Questionnaires were completed on paper, at home in a private setting, and sealed in envelopes to ensure confidentiality.
Composite scores were created by summing item scores on each of 4 subscales relevant to adolescent mental illness: conduct disorder (6 items, e.g., "I kick or hit other people my age"), hyperactivity (7 items, e.g., "I am impulsive, I act without thinking"), indirect aggression (5 items, e.g., "When I am mad at someone, I say bad things behind his/her back"), and symptoms of depression/anxiety (7 items, e.g., "I am not as happy as other people my age" and "I worry a lot"). ${ }^{19}$ The same items were collected at each cycle, with the exception of 1 hyperactivity item and 1 depression/anxiety item, which were dropped in cycle 4 . In the interest of comparability over time, these items were not included in composite scores. All items comprising the final scale are presented in Appendix 1, (available at www.cmaj.ca/lookup/suppl/doi:10.1503/cmaj.14 0064/-/DC1), and frequencies of individual responses to each item are presented in Appendix 2 (available at www.cmaj.ca/lookup/suppl /doi:10.1503/cmaj.140064/-/DC1). Participants with missing data were excluded. The composite scores showed good internal consistency, as assessed by Cronbach $\alpha$. The $\alpha$ values ranged from 0.73 (indirect aggression) to 0.79 (depression and anxiety).

Suicidal ideation was assessed by asking the participant, "During the past 12 months, did you seriously consider attempting suicide?" Those who answered yes were additionally asked, "During the past 12 months, how many times did you attempt suicide?"

\section{Covariates}

Family socioeconomic status was based on the ratio of family income to corresponding lowincome cut-off (i.e., the level below which a family is likely to spend a larger proportion of their income on necessities than the average family), calculated based on family size and area of residence. Rural or urban residence was

Table 1: Sample characteristics of participants in the National Longitudinal Survey of Children and Youth, by cycle

\begin{tabular}{|c|c|c|c|c|c|c|c|c|}
\hline \multirow[b]{2}{*}{ Characteristic } & \multicolumn{8}{|c|}{$\%$ of participants* } \\
\hline & $\begin{array}{c}\text { Cycle } 1 \\
(1994 / 95)\end{array}$ & $\begin{array}{c}\text { Cycle 2 } \\
(1996 / 97)\end{array}$ & $\begin{array}{c}\text { Cycle } 3 \\
(1998 / 99)\end{array}$ & $\begin{array}{c}\text { Cycle } 4 \\
(2000 / 01)\end{array}$ & $\begin{array}{c}\text { Cycle 5 } \\
(2002 / 03)\end{array}$ & $\begin{array}{c}\text { Cycle } 6 \\
(2004 / 05)\end{array}$ & $\begin{array}{c}\text { Cycle } 7 \\
(2006 / 07)\end{array}$ & $\begin{array}{c}\text { Cycle } 8 \\
(2008 / 09)\end{array}$ \\
\hline Male sex & 51.33 & 51.34 & 51.35 & 51.25 & 51.07 & 51.12 & 51.08 & 51.14 \\
\hline $\begin{array}{l}\text { Rural } \\
\text { residence }\end{array}$ & 19.92 & 13.86 & 14.41 & 13.84 & 12.17 & 12.56 & 17.09 & 15.87 \\
\hline $\begin{array}{l}\text { Note: } \text { LICO = low } \\
\text { *Percentages are } \\
\text { +Low income cu }\end{array}$ & $\begin{array}{l}\text { e cut-off. } \\
\text { ted using } \\
\text { alculated }\end{array}$ & $\begin{array}{l}\text { te cycle } \\
\text { family by }\end{array}$ & . & 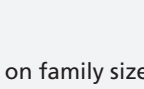 & 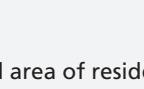 & & & \\
\hline
\end{tabular}




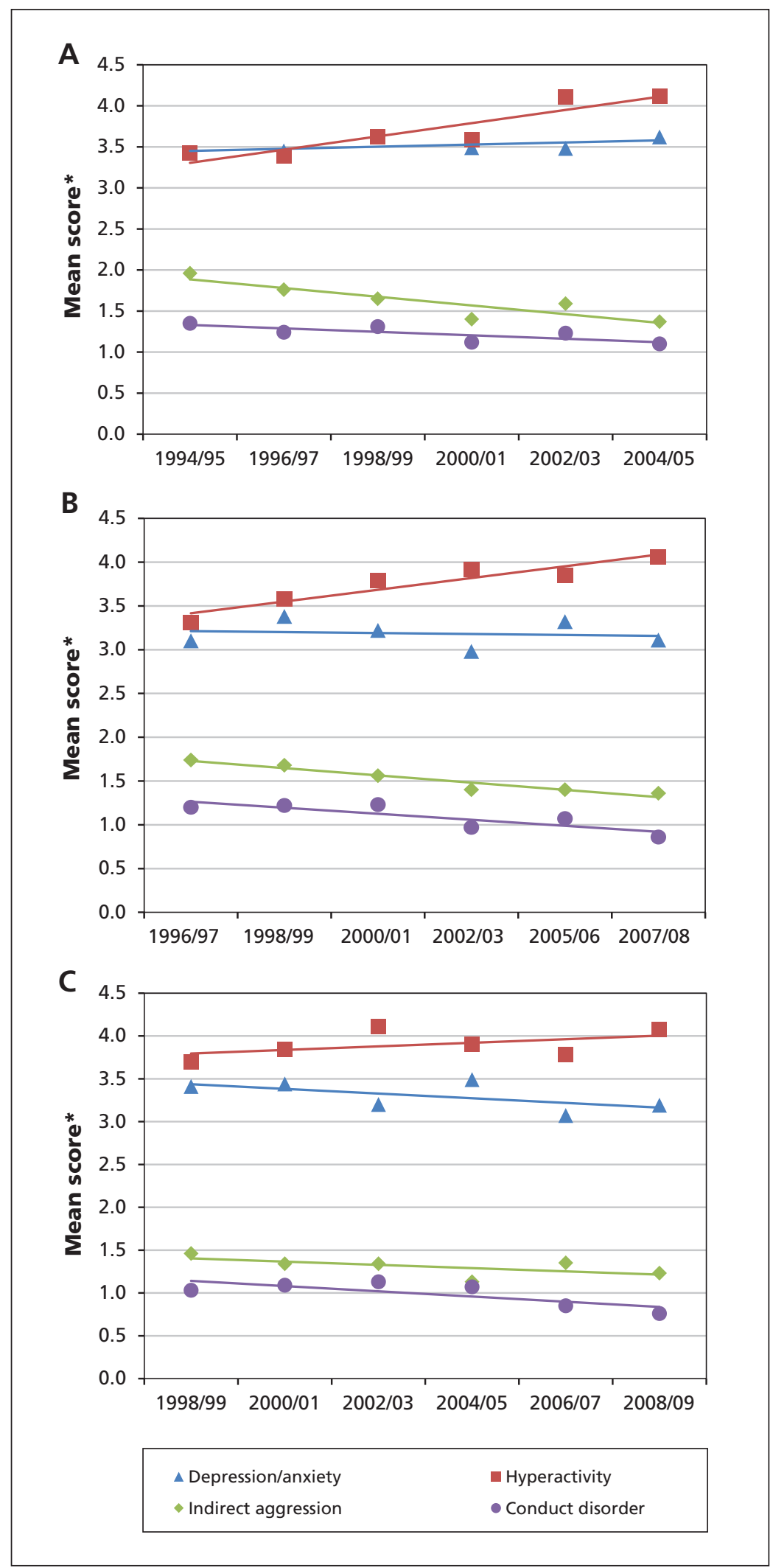

Figure 1: Mean scores for symptoms of mental illness between 1994/95 and 2004/05 in participants aged 10-11 years (A), between 1996/97 and 2007/08 in those aged 12-13 years (B) and between 1998/99 and 2008/09 in those aged 14-15 years (C). *Higher scores indicate greater symptoms. Possible scores range from 0 to 14 for depression/anxiety and hyperactivity, 0 to 10 for indirect aggression and 0 to 12 for conduct disorder. assessed based on postal code. The sex of the child was reported by parents.

\section{Statistical analysis}

Mean scores on conduct, indirect aggression, hyperactivity, and depression and anxiety scales were compared across all cycles. We used linear regression treating time as a continuous variable to test for significant cross-sectional trends in mean scores. In addition, we examined trends in the proportion of individuals reporting suicidal ideation and suicide attempt. To account for the complex survey design, we included normalized sampling weights in the analyses. We used cross-sectional weights to represent the Canadian population at each cycle.

We conducted a sensitivity analysis to test whether the percentage of children with high symptom levels followed a similar pattern over time. For each outcome, a cut-off score was identified based on the top decile at the first available time point for each age group. Trend analysis was conducted to determine whether the percentage of children exceeding these cut-off scores changed over time.

We examined interactions with covariates to test whether linear trends differed for different subgroups of the population (e.g., rural or urban, low income). Interactions with sex were also examined, considering the documented sex differences in prevalence of mental health outcomes, including depression, externalizing behaviours and suicide. ${ }^{20-22}$ No interactions suggesting an increase in mental illness symptoms for any subgroups were found. Therefore, we present results for all subgroups together within each age-group sample.

Given that sample attrition may result in biased estimates of changes in rates of mental illness symptoms over time, ${ }^{23}$ we also examined the association between symptoms of mental illness at age 8-9 years and dropout at ages 10-11, 12-13 and 14-15 years.

\section{Results}

The sample for the present study included 11725 participants who reported at age 10-11 years (1994/95-2004/05), 10574 who reported at age 12-13 years (1996/97-2006/07) and 9835 who reported at age 14-15 years (1998/992008/09). Participant characteristics are presented in Table 1. Mean scores on the depression and anxiety scale did not change significantly over time among participants aged 10-11 years (0.03 per 2-year cycle, 95\% CI -0.01 to 0.07 ) (Figure 1A; Appendix 3, available at www.cmaj.ca/lookup/suppl/doi:10.1503/cmaj 
$.140064 /-/ D C 1)$ and among participants aged $12-13$ years $(-0.01,95 \%$ CI -0.05 to 0.03$)$ (Figure 1B, Appendix 3). There was evidence of a small but significant decrease in mean depression and anxiety scores over time for children aged $14-15$ years $(-0.06,95 \% \mathrm{CI}-0.10$ to -0.01) (Figure 1C, Appendix 3).

Indicators of conduct disorder and indirect aggression decreased slightly but significantly over time in all age groups (Figure 1, Appendix 3). Changes per 2-year cycle in mean scores on the conduct disorder scale decreased among participants aged $10-11$ years $(-0.04,95 \%$ CI -0.07 to -0.04$), 12-13$ years $(-0.07,95 \% \mathrm{CI}$ -0.10 to -0.04$)$ and $14-15$ years $(-0.06,95 \%$ CI -0.09 to -0.03$)$. Similarly, changes per 2-year cycle in mean scores on the indirect aggression scale decreased among participants aged $10-11$ years $(-0.11,95 \%$ CI -0.13 to $-0.08), 12-13$ years $(-0.08,95 \% \mathrm{CI}-0.11$ to $-0.05)$ and $14-15$ years $(-0.04,95 \%$ CI -0.07 to -0.01$)$.

In contrast, there was a significant increase in mean hyperactivity scores (Figure 1, Appendix 3) among participants aged 10-11 years (change per 2-year cycle, $0.16,95 \%$ CI 0.02 to 0.12 ) and participants aged $12-13$ years $(0.13,95 \%$ CI 0.09 to 0.18 ), but not among those aged $14-15$ years $(0.04,95 \% \mathrm{CI}-0.01$ to 0.09$)$.

The proportion of participants aged 12-13 and 14-15 years who reported having considered or attempted suicide in the past 12 months declined moderately from $1998 / 99$ to $2008 / 09$ (Figure 2; Appendix 3, supplemental tables 4-5). The percentage of participants aged $12-13$ years who had attempted suicide significantly decreased by $0.40 \%$ with each 2 -year cycle $(95 \%$ CI -0.78 to -0.07$)$. We also found declining trends in the percentage of adolescents aged $14-15$ years who had considered $(-0.92 \%, 95 \%$ CI -1.39 to -0.45$)$ and attempted suicide $(-0.56 \%$, $95 \%$ CI -0.91 to -0.23 ).

The pattern of results for the sensitivity analysis was nearly identical to that found using mean symptom levels (Figure 3; Appendix 3, supplemental tables 6-8). The only exceptions were among adolescents aged 14-15 years, for whom the percentage reporting high levels of hyperactivity increased significantly over time (change per 2-year cycle, $0.68 \%, 95 \%$ CI 0.15 to 1.22 ), but the percentage with high depression and anxiety scores did not change significantly over time $(0.0 \%, 95 \% \mathrm{CI}-0.4$ to 0.4$)$.

Attrition analysis suggested that the drop-out rate among participants aged 10-15 years was significantly associated with lower symptoms of mental illness at age 8-9 years (data not shown).

\section{Interpretation}

Our results suggest that, with the exception of hyperactivity, the prevalence of symptoms of mental health disorders in Canadian children and adolescents is not increasing. In fact, the results suggest that some symptoms of mental illness and behavioural problems seem to be decreasing (i.e., indirect aggression, conduct disorder and suicide attempts). We did find evidence of an increase in hyperactivity among participants aged 10-11 and 12-13 years.

Several studies done in the United States and other countries have reported that the prevalence of mental health disorders in adolescents is increasing. ${ }^{3-7}$ The current study contrasts with the previous literature by showing relatively stable or declining prevalence between 1994/95 and 2008/09.

There is still a great deal of debate as to the direction of temporal trends in rates of mental illness. Results of meta-analysis support the finding that rates of depression have remained similarly stable among children and adolescents, ${ }^{20}$ and a recent systematic review reported that most stud-

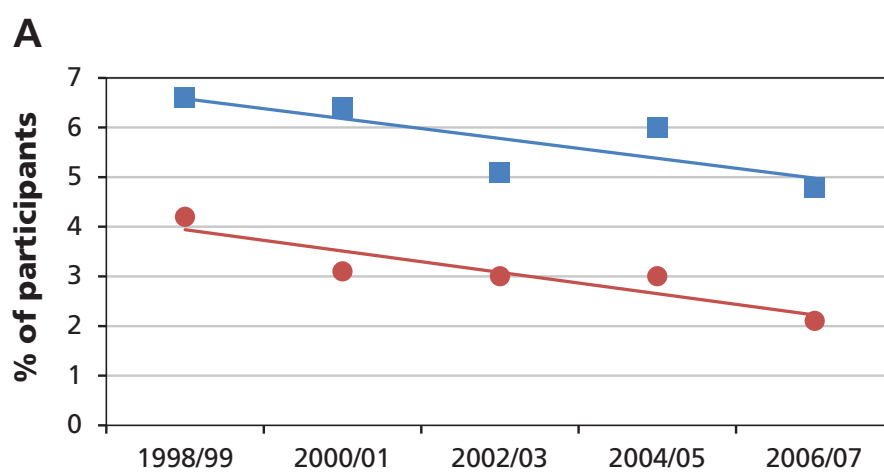

B

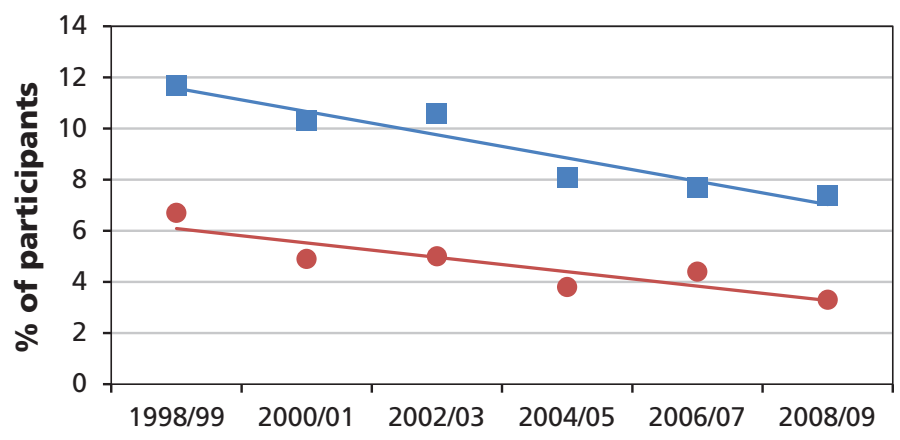

- Suicidal ideation $\quad$ Suicide attempt

Figure 2: Trends in suicidal ideation and suicide attempt between 1998/99 and 2006/07 in participants aged 12-13 years (A) and between 1998/99 and 2008/09 in those aged $14-15$ years (B). 
ies suggest similar stability in rates of externalizing problems among children and adolescents. ${ }^{24}$

Discrepancies in the literature surrounding trends in the prevalence of mental illness in the population may be due in part to differences in

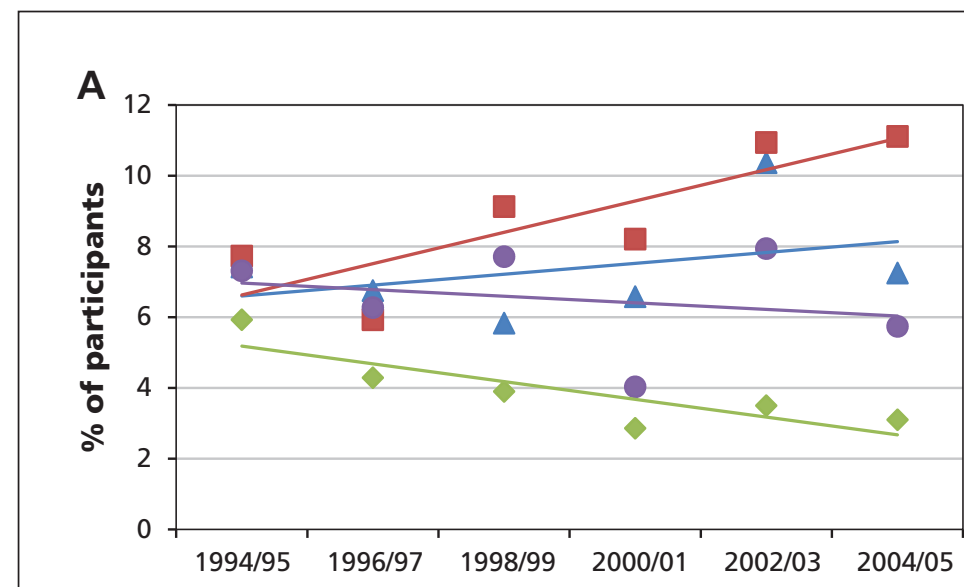

B

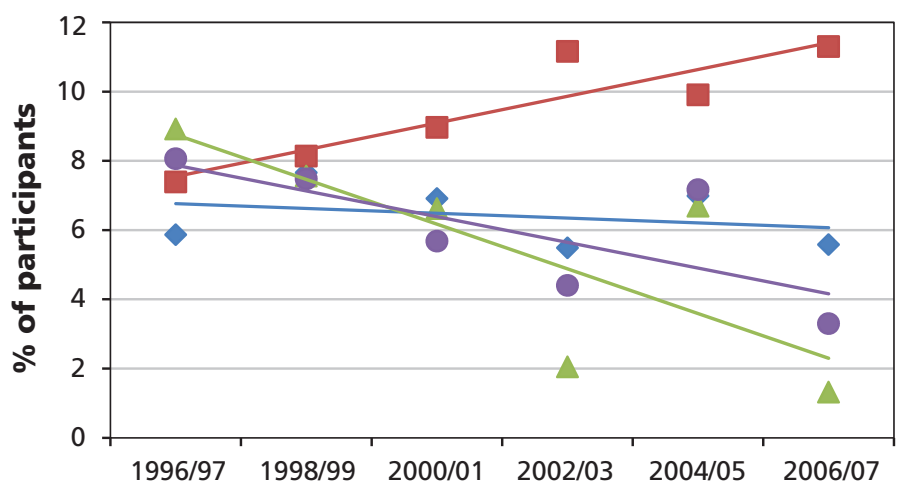

C

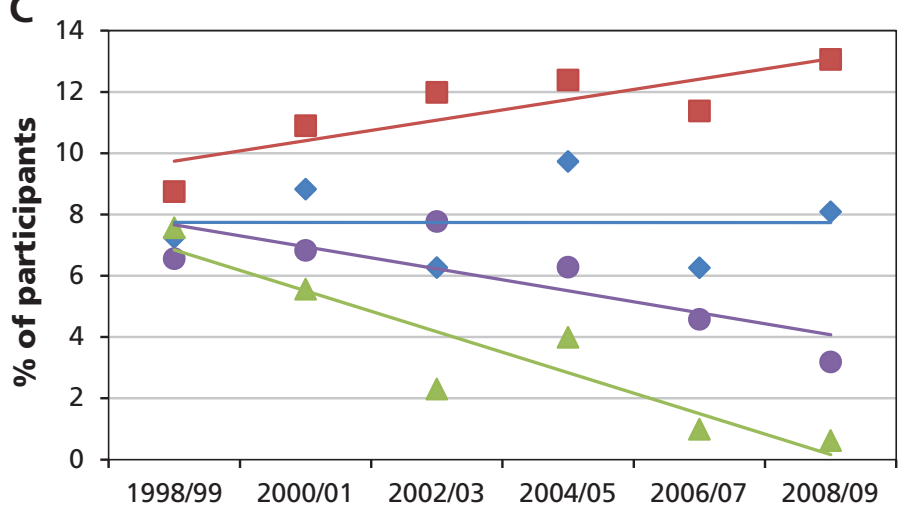

$\Delta$ Depression/anxiety

- Indirect aggression

- Hyperactivity

- Conduct disorder

Figure 3: Trends in high scores on mental health indices between 1994/95 and 2004/05 in participants aged 10-11 years (A), between 1996/97 and 2006/07 in those aged 12-13 years (B) and between 1998/99 and 2008/09 in those aged 14-15 years (C). Cut-off scores were calculated based on the top decile at the first available cycle for each age group. measurement. Some studies report results based on disorders diagnosed by a health professional, ${ }^{6,9}$ and others report results based on faceto-face interviews $s^{8,11,25}$ or reports of symptoms from parents or teachers. ${ }^{3,4}$ The present study used self-report assessments of symptoms, which may explain why these results differ from some studies. Considerable changes have been made in diagnostic criteria for mental illness, and methods of diagnosing childhood disorders have greatly improved. ${ }^{26}$ Some studies using a clinical diagnosis of depression have noted increases in rates of mental health problems ${ }^{6,7}$ One national Canadian study reported that although self-reported distress symptoms remained stable over time in adults, clinical diagnosis of mood disorders, as well as self-reported antidepressant use, showed an increase..$^{10}$ However, such results may reflect changes in treatment-seeking behaviour. ${ }^{27}$

There have been substantial efforts made to reduce the stigma surrounding mental illness, ${ }^{28,29}$ and awareness of mental illness has increased among medical professionals and the general public. ${ }^{28-30}$ As mental health literacy increases, parents and caregivers are presumably more likely to recognize mental health problems and refer children to professional care. ${ }^{31,32}$ This may explain why studies using reports from parents and teachers have reported increases in rates of child and adolescent mental illness, ${ }^{3,4}$ and why diagnosed rates of mental health problems have increased in recent years. ${ }^{6,7}$ However, recent research suggests that most youth experiencing mental health problems are still not accessing treatment. ${ }^{28,33,34}$ Continued effort is needed to reduce barriers to helpseeking behaviour among youth.

Given advances in diagnosis and treatment of mental illness among adolescents, it is possible that observed decreases in symptoms over time may be due to successful treatment. There has been a reported increase in the prescription of stimulants $^{35-37}$ and antidepressants ${ }^{10,36-40}$ for children and adolescents in recent years.

In the present study, we found that there was a moderate increase over time in mean hyperactivity score in participants aged $10-11$ and $12-13$ years. Although these increases were statistically significant, it is unknown whether the magnitude of this change would be considered clinically significant. Previous work has found an upward trend in the prevalence of prescribed medications for attention-deficit/hyperactivity disorder (ADHD) and diagnoses of ADHD in Canadian school-aged children. ${ }^{7,35}$ A similar upward trend has been reported for US children (aged 3-17 yr) over the same period. ${ }^{41-43}$ Some authors have hypothesized that increases in ADHD over time may be due to increasing exposure to etiological 
factors, such as environmental contaminants. ${ }^{43}$ Other environmental factors, such as the increasing ubiquity of electronic media ${ }^{44}$ may also contribute to increases in ADHD symptoms over time, though more research is needed to confirm a causal association.

\section{Strengths and limitations}

This study has several methodologic strengths. It comprises a large population-based sample broadly representative of the Canadian population. The survey repeatedly included a series of questions relevant to many aspects of mental health. The use of a set of identical instruments and items regarding symptoms of mental illness over a prolonged period provided an excellent opportunity to examine historical trends.

Limitations of this study should be noted. This study used self-reported assessment of symptoms on a continuous scale to measure mental illness rather than a clinical diagnosis. This may be considered an advantage because we were able to include children with moderate or subthreshold symptoms.

The observed stability in rates of mental illness symptoms over time may be due to sample attrition. That is, it is possible that participants with higher scores on symptoms of mental illness may be more likely to drop out of the study over time, which could lead to lower estimates of the rates of mental illness in later collection cycles. However, in the present sample, higher scores on symptoms of mental illness at ages 8-9 years were associated with a lower likelihood of dropping out of the sample at ages 10-15 years, as has been reported in other studies using this cohort. ${ }^{45}$

The present study reports trends in symptoms of mental illness among youth for the period from $1994 / 95$ to $2008 / 09$. Continued research is necessary to understand how trends may have changed in the time since these data were collected.

\section{Conclusion}

Our results suggest that, contrary to popular media reports, symptoms of mental illness (with the exception of hyperactivity) are not increasing among Canadian adolescents. An accurate understanding of trends in adolescent mental health is fundamental to appropriately plan public health services and policy. There has been an increase in suicide prevention efforts since the mid-1990s. ${ }^{46,47}$ Encouragingly, results from this study suggest that suicidal ideation and suicide attempts may be declining. This finding is supported by studies that reported a recent decline in suicide rates $^{48-50}$ and attempts $^{51}$ among Canadian and American youth. Though there is no conclusive evidence for the efficacy of various efforts in preventing suicide, ${ }^{52}$ some strategies, including physician education and certain school-based strategies, show promise in reducing suicidal behaviours. ${ }^{46,47,50,53}$ Continued effort in suicide prevention, rigorous research into the efficacy of prevention programs, and improved interventions targeting mental illness in adolescents is crucial for improving the mental health of Canadian adolescents.

\section{References}

1. Compton WM, Conway KP, Stinson FS, et al. Changes in the prevalence of major depression and comorbid substance use disorders in the United States between 1991-1992 and 2001-2002. Am J Psychiatry 2006;163:2141-7.

2. Goldney RD, Eckert KA, Hawthorne G, et al. Changes in the prevalence of major depression in an Australian community sample between 1998 and 2008. Aust N Z J Psychiatry 2010;44: 901-10.

3. Achenbach TM, Howell CT. Are American children's problems getting worse? A 13-year comparison. J Am Acad Child Adolesc Psychiatry 1993;32:1145-54.

4. Collishaw S, Maughan B, Goodman R, et al. Time trends in adolescent mental health. J Child Psychol Psychiatry 2004;45: 1350-62.

5. Lewinsohn PM, Rohde P, Seeley JR, et al. Age-cohort changes in the lifetime occurrence of depression and other mental disorders. J Abnorm Psychol 1993;102:110-20.

6. Zwaanswijk M, van Dijk CE, Verheij RA. Child and adolescent mental health care in Dutch general practice: time trend analyses. BMC Fam Pract 2011;12:133.

7. Kelleher KJ, McInerny TK, Gardner WP, et al. Increasing identification of psychosocial problems: 1979-1996. Pediatrics 2000;105:1313-21.

8. Mattisson C, Bogren M, Nettelbladt P, et al. First incidence depression in the Lundby study: a comparison of the two time periods 1947-1972 and 1972-1997. J Affect Disord 2005;87: 151-60.

9. Walters K, Rait G, Griffin M, et al. Recent trends in the incidence of anxiety diagnoses and symptoms in primary care. PLoS ONE 2012;7:e41670

10. Simpson KRS, Meadows GN, Frances AJ, et al. Is mental health in the Canadian population changing over time? Can J Psychiatry 2012;57:324-31.

11. Murphy JM, Horton NJ, Laird NM, et al. Anxiety and depression: a 40-year perspective on relationships regarding prevalence, distribution, and comorbidity. Acta Psychiatr Scand 2004;109:355-75.

12. Changing directions, changing lives: the mental health strategy for Canada. Calgary: Mental Health Commission of Canada; 2012.

13. Rait G, Walters K, Griffin M, et al. Recent trends in the incidence of recorded depression in primary care. Br J Psychiatry 2009; 195:520-4.

14. Growing up in Canada: national longitudinal survey of children and youth. Ottawa: Statistics Canada; 1992.

15. National longitudinal survey of children and youth, cycle $8-$ user guide. Ottawa: Statistics Canada; 2009.

16. Boyle MH, Offord DR, Racine Y, et al. Evaluation of the original Ontario Child Health Study scales. Can J Psychiatry 1993; 38:397-405.

17. Weeks M, Wild TC, Ploubidis GB, et al. Childhood cognitive ability and its relationship with anxiety and depression in adolescence. J Affect Disord 2014;152-154:139-45.

18. Elgar FJ, Mills RS, McGrath PJ, et al. Maternal and paternal depressive symptoms and child maladjustment: the mediating role of parental behavior. J Abnorm Child Psychol 2007;35:943-55.

19. National longitudinal survey of children and youth, cycle 7 user guide. Ottawa: Statistics Canada; 2007.

20. Avison WR, Mcalpine DD. Gender differences in symptoms of depression among adolescents. J Health Soc Behav 1992;33:77-96.

21. Baillargeon RH, Zoccolillo M, Keenan K, et al. Gender differences in physical aggression: a prospective population-based survey of children before and after 2 years of age. Dev Psychol 2007; $43: 13-26$.

22. Skinner R, McFaull S. Suicide among children and adolescents in Canada: trends and sex differences, 1980-2008. CMAJ 2012. 184:1029-34.

23. Wolke D, Waylen A, Samara M, et al. Selective drop-out in longitudinal studies and non-biased prediction of behaviour disorders. 
Br J Psychiatry 2009; 195:249-56.

24. Bor W, Dean AJ, Najman J, et al. Are child and adolescent mental health problems increasing in the 21 st century? A systematic review. Aust N Z J Psychiatry 2014;48:606-16.

25. Lewinsohn PM, Rohde P, Seeley JR, et al. Natural course of adolescent major depressive disorder in a community sample: predictors of recurrence in young adults. Am J Psychiatry 2000; 157:1584-91.

26. Costello EJ, Egger H, Angold A. 10-year research update review: the epidemiology of child and adolescent psychiatric disorders: I. Methods and public health burden. J Am Acad Child Adolesc Psychiatry 2005;44:972-86.

27. Mojtabai R. Americans' attitudes toward mental health treatment seeking: 1990-2003. Psychiatr Serv 2007;58:642-51.

28. Wei Y, Hayden JA, Kutcher S, et al. The effectiveness of school mental health literacy programs to address knowledge, attitudes and help seeking among youth. Early Interv Psychiatry 2013; 7:109-21.

29. Jorm AF. Mental health literacy. Public knowledge and beliefs about mental disorders. Br J Psychiatry 2000;177:396-401.

30. Reavley NJ, Jorm AF. Public recognition of mental disorders and beliefs about treatment: changes in Australia over 16 years. Br J Psychiatry 2012;200:419-25.

31. Whitely J, Smith JD, Vaillancourt T. Promoting mental health literacy among educators critical in school-based prevention and intervention. Can J Sch Psychol 2013;28:56-70.

32. Loades ME, Mastroyannopoulou K. Teachers' recognition of children's mental health problems. Child Adolesc Ment Health 2010;15:150-6.

33. Mariu KR, Merry SN, Robinson EM, et al. Seeking professional help for mental health problems, among New Zealand secondary school students. Clin Child Psychol Psychiatry 2012;17:284-97.

34. Rickwood DJ, Deane FP, Wilson CJ. When and how do young people seek professional help for mental health problems? Med J Aust 2007; 187(Suppl):S35-9.

35. Brault MC, Lacourse E. Prevalence of prescribed attention-deficit hyperactivity disorder medications and diagnosis among Canadian preschoolers and school-age children: 1994-2007. Can J Psychiatry 2012;57:93-101

36. Rushton JL, Whitmire JT. Pediatric stimulant and selective serotonin reuptake inhibitor prescription trends: 1992 to 1998. Arch Pediatr Adolesc Med 2001;155:560-5.

37. Olfson M, Marcus SC, Weissman MM, et al. National trends in the use of psychotropic medications by children. J Am Acad Child Adolesc Psychiatry 2002;41:514-21.

38. Murray ML, de Vries CS, Wong ICK. A drug utilisation study of antidepressants in children and adolescents using the general practice research database. Arch Dis Child 2004;89:1098-102.

39. Wijlaars LPMM, Nazareth I, Petersen I. Trends in depression and antidepressant prescribing in children and adolescents: a cohort study in The Health Improvement Network (THIN). PLoS ONE 2012; 7:e33181.

40. Meng X, D'Arcy C, Tempier R. Long-term trend in pediatric antidepressant use, 1983-2007: a population-based study. Can J Psychiatry 2014;59:89-97.

41. Boyle CA, Boulet S, Schieve LA, et al. Trends in the prevalence of developmental disabilities in us children, 1997-2008. Pediatrics 2011;127:1034-42.

42. Akinbami LJ, Liu X, Pastor PN, Reuben CA. Attention deficit hyperactivity disorder among children aged 5-17 years in the United States, 1998-2009. NCHS Data Brief 2011;70:1-8.

43. Visser SN, Danielson ML, Bitsko RH, et al. Trends in the parentreport of health care provider-diagnosed and medicated attentiondeficit/hyperactivity disorder: United States, 2003-2011. J Am Acad Child Adolesc Psychiatry 2014:53:34-46 e2.

44. Gentile DA, Swing EL, Lim CG, et al. Video game playing, attention problems, and impulsiveness: evidence of bidirectional causality. Psychol Pop Media Cult 2012;1:62-70.

45. Browne DT, Odueyungbo A, Thabane L, et al. Parenting-bygender interactions in child psychopathology: attempting to address inconsistencies with a Canadian national database. Child Adolesc Psychiatry Ment Health 2010;4:5.

46. Miller DN, Eckert TL, Mazza JJ. Suicide prevention programs in the schools: a review and public health perspective. School Psych Rev 2009;38:168-88.

47. Katz C, Bolton SL, Katz LY, et al. A systematic review of school-based suicide prevention programs. Depress Anxiety 2013;30:1030-45.

48. Langlois S, Morrison P. Suicide deaths and suicide attempts. Health Rep 2002;13:9-22.

49. Kutcher SP, Szumilas M. Youth suicide prevention. CMAJ 2008;29;178:282-5.

50. Gould MS, Greenberg T, Velting DM, et al. Youth suicide risk and preventive interventions: a review of the past 10 years. $J \mathrm{Am}$ Acad Child Adolesc Psychiatry 2003;42:386-405.

51. Rhodes AE, Bethell J, Carlisle C, et al. Time trends in suiciderelated behaviours in girls and boys. Can J Psychiatry 2014;59: $152-9$.

52. Robinson J, Cox G, Malone A, et al. A systematic review of school-based interventions aimed at preventing, treating, and responding to suicide-related behavior in young people. Crisis 2013;34:164-82

53. Mann JJ, Apter A, Bertolote J, et al. Suicide prevention strategies: a systematic review. JAMA 2005;294:2064-74.

Affiliation: Department of Epidemiology and Community Medicine, University of Ottawa, Ottawa, Ont.

Contributors: Ian Colman conceived and designed the study. Seanna McMartin and Mila Kingsbury performed the data analysis and wrote the manuscript. All of the authors contributed to the study design, interpreted the results, revised the manuscript, approved the final version submitted for publication and agree to act as guarantors of the work.

Funding: This research was supported by a grant from the SickKids Foundation and the Canadian Institutes of Health Research (grant no. SKF 116328), as well as funding from the Canada Research Chairs program for Ian Colman. The funders had no role in the design or conduct of the study; the collection, management, analysis or interpretation of the data; the preparation, review or approval of the manuscript; or the decision to submit the manuscript for publication. The research and analysis are based on data from Statistics Canada; the opinions expressed do not represent the views of Statistics Canada. 